\title{
Knowledge, Attitude, and Practice Regarding Cervical Cancer among Rural Community Women in Northeast Thailand
}

\author{
Cholticha Mongsawaeng ${ }^{1}$, Nawaporn Kokorn ${ }^{1}$, Jirawoot Kujapun ${ }^{1}$, Jun Norkaew ${ }^{1}$, \\ Nusorn Kootanavanichpong ${ }^{1}$, Wasugree Chavenkun ${ }^{1}$, Sukanya Ponphimai', \\ Soraya J Kaewpitoon ${ }^{2,3}$, Taweesak Tongtawee ${ }^{3}$, Natnapa Padchasuwan ${ }^{4}$, Prasit \\ Pengsaa $^{1}$, Pontip Kompor ${ }^{1}$, Natthawut Kaewpitoon ${ }^{1,2,3 *}$
}

\begin{abstract}
Background: Cervical cancer is the second most common malignancy among women worldwide, and women of reproductive age in Thailand. However, information on the behavior regarding cervical cancer in rural community Thailand is sparse. Objective: To assess the knowledge, attitude, and practice regarding cervical cancer (CC) among rural community women in Nakhon Ratchasima, Thailand, using predesigned structured questionnaires. Materials and Methods: A cross-sectional survey was conducted in 8 villages of Non Sung district, Nakhon Ratchasima province, Thailand, during January to April 2015. Bloom's taxonomy was used as a framework for the study. 265 women aged between 30-60 years old were selected by simple random sampling. All participants completed predesigned questionnaires with $\mathbf{4}$ parts: demographic data, knowledge, attitude, and practice regarding cervical cancer. Descriptive statistics were used for analysis in this study. Results: The majority of participants were in the age group of 41-50 years old (42.6\%) with senior secondary school level of education (32.1\%), marriage status $(\mathbf{8 5 . 0 \%})$, agricultural employment $(59.6 \%)$, and family income between 6,00010,000 baht per month $(54.3 \%)$. Some $63.4 \%$ and $68.7 \%$ participants had high knowledge and moderate level of attitudes regarding $\mathrm{CC}$, while $41.1 \%, 48.7 \%$, and $10.2 \%$ had neem regularly, irregularly or never screened for CC, respectively. The main reasons for not screening were were shyness $(44.4 \%)$ and no time $(55.6 \%)$. Vaginal discharge and itching were the common signs and symptoms of participants who were screened at a health promotion hospital of sub-district. Conclusions: $\mathrm{CC}$ is still a health problem in the rural community. Therefore, health education is required, particularly for those who have never undergone screening.
\end{abstract}

Keywords: Knowledge - attitude - practice - cervical cancer - rural communities - North-East Thailand

Asian Pac J Cancer Prev, 17 (1), 85-88

\section{Introduction}

Cervical cancer (CC) is the second most common malignancy among women worldwide. It was estimated approximately 528,000 cases and 266,000 deaths in 2012 . Of $70 \%$ CC occur in developing countries. It is due to the abnormal growth of cells that are typically no symptoms in early stage, later symptoms may include abnormal vaginal bleeding, discharge, and itching, and pelvic pain (Stewart and Wild 2014). Many risk factors of CC have been characterized. More than $90 \%$ of cases were associated to Human papillomavirus (HPV) infection that involved in the development (Kumar et al., 2007; Hong et al., 2009). Other risk factors include starting sex at a young age and having many sexual partners, birth control pills, smoking, and a weak immune system (Brisson et al., 1994; Kumar et al., 2007; Hong et al., 2009; Stewart and Wild, 2014). CC typically develops over 10 to 20 years from precancerous change (Stewart and Wild, 2014). About $90 \%$ and $10 \%$ are squamous cell carcinoma and adenocarcinoma, respectively. Cervical screening, biopsy, and medical imaging are typically diagnosis (Kumar et al., 2007; Hong et al., 2009).

Pap smear is the method used for CC screening that can identify precancerous changes which when treated can prevent the development of cancer. Other methods of prevention included having few sexual partners and the use of condom (World Health Organization 2014). Worldwide, CC is the most common cause of cancer and the most common cause of death from cancer in women (Stewart and Wild, 2014). The most of CC occur in developing countries including Thailand. In Thailand, the average annual CC incidence rate was 65.2 cases per 100,000 between the years 1983 and 2002, this figures indicates that its the most common cancer among women between 30-74 years of age (Vaccarella et al., 2013; Marks

${ }^{I}$ Department of Public Health, Faculty of Public Health, Vongchavalitkul University, ${ }^{2}$ Parasitic Disease Research, Institute of Medicine, Suranaree University of Technology, ${ }^{3}$ Division of Research Clinic, Suranaree University of Technology Hospital, Nakhon Ratchasima ${ }^{4}$ Faculty of Public Health, Khon Kaen University, Khon Kaen Thailand *For correspondence: natthawut.k@hotmail. com,natthawut_kae@vu.ac.th 
Cholticha Mongsawaeng et al

et al., 2015). To reduce this CC, prevention and control in Thailand are need required. In developed countries, checking the cervix for $\mathrm{CC}$ has been credited with dramatically reducing the number of cases of and mortality from CC (Canavan and Doshi, 2000). Educational materials help increase the likelihood women will go for screening (Everett et al., 2011). In Lum Khao sub-districts, 850 women are age between 30-60 years old, but only $8 \%$ of them had screened CC (Health promotion hospital of Lum Khao sub-district, 2014). This figure shows that awareness of women at risk is low, therefore, the assess the knowledge, attitude, and practice regarding CC among rural community women in Nakhon Ratchasima, Thailand using predesigned structured questionnaires, is conducted. The results may useful for further CC planning of prevention and control.

\section{Materials and Methods}

This cross-sectional study was conducted in Lum Khao sub-district, Non Sung district, Nakhon Ratchasima province, northeastern Thailand. It is locate in the north part of Non Sung district and the central part of Nakhon Ratchasima province where approximately 309 kilometers from Bangkok; capital of Thailand, and 48.5 kilometers from Mueang district of Nakhon Ratchasima province. This village is covered 100.22 kilometers2, 17 villages, and 1,975 households (Figure 1).

\section{Population, sample size, and sampling}

The 265 participants were selected from 850 women by using the sample size calculated equation of Krejcie and Morgan (1970) and simple random sampling, included participants age between 30-60 years old from 8 villages of Lum Khao sub-district, Non Sung district, Nakhon Ratchasima Province, northeastern Thailand during January and April 2015.

\section{Measurement and data collection}

A predesigned questionnaire was utilized to collect the data from 265 participants. The questionnaire comprised of 4 parts including (1) demographic data; age, marital status, education, occupation, family income, and number of children, (2) knowledge regarding to CC; sign and symptom, cause, diagnosis, treatment, and prevention, (3) attitude; awareness of CC prevention and control, and (4) practice regarding experiences to screen CC. Reliability and validity of questionnaire was analyzed, knowledge (Kruder-Richardon-20) $=0.70$, attitude and practice (coefficient of Cronbach's alpha) $=0.70$ and 0.70 , respectively. One participant between 30-60 years of age, who had been living in sub-district for at least 6 months, was random chosen within each villages at the time of visiting by a research assistant. Necessary permission from the concerned authorities was taken and a survey was conducted using a predesigned KAP questionnaire. Prior informed consent was taken. For those not available in the first interview another visit was made to minimize non-response.

\section{Statistical analysis}

Descriptive statistical data were analyzed with SPSS software for demographic data, knowledge, attitude, and practice regarding CC. Each questionnaire was analyzed and interpreted for their parts. Evaluation of knowledge level was calculated and analyzed according to Bloom et al. (1971), answer correct=1, incorrect=0, and interpreted to high level; 19-21 point, fair level; $13-18$ point, 0-12; low level. Evaluation of attitude level was calculated and analyzed according to Best et al. (1997), attitude with 4 choices (exactly agree, agree, dis-agree, exactly dis-agree): positive question $=4,3,2,1$, negative question $=1,2,3,4$, and interpreted to good level; 2.67-3.00 point, moderate level; 1.33-2.66 point, 1.00-1.32 point; poor level. Practice with 3 choices: regular, irregular, and never.

\section{Results}

A majority of participants were age group 41-50 years old $(42.6 \%)$, senior secondary school level (32.1\%), marriage status $(85.0 \%)$, agriculture $(59.6 \%)$, and family income between 6,000-10,000 baht per month (54.3\%) (Table 1). Of $63.4 \%$ participants had a high knowledge regarding to $\mathrm{CC}$ (Table 2). The high scores were found in the question of "Cervical cancer is a chronic inflammation of cervix". The low scores were found in the question of "Starting sex at a young age is a risk factor to CC" and followed "Long-term use of combined oral contraceptives is associated with an increased risk of CC diagnosis". Of $68.7 \%$ participants had a moderate level of attitude regarding $\mathrm{CC}$. The high scores were found in the question of "Need to screen the CC with female public health officer". The low scores were found in the question of

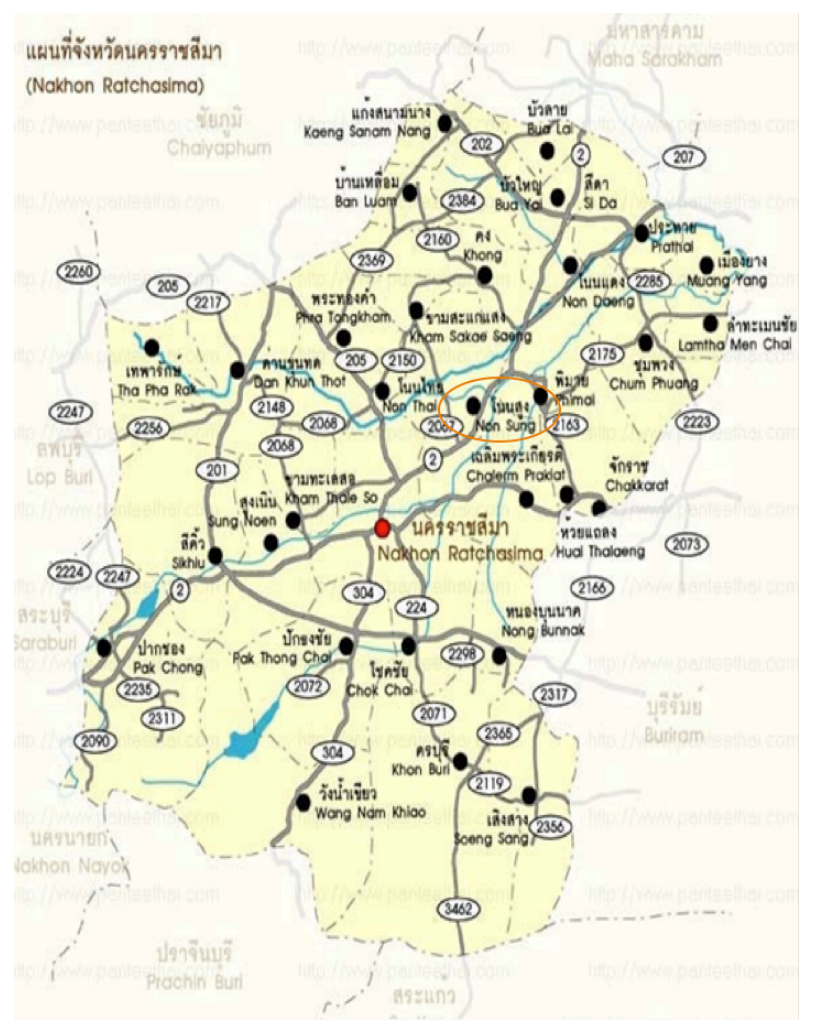

Figure 1. Map of Non Sung district, Nakhon Ratchasima Province, Northeast, Thailand 
Knowledge, Attitude, and Practice Regarding Cervical Cancer among Rural Community Women in Northeast Thailand

Table 1. Demographic data of 265 participants from 8 villages of Lum Khao sub-district, Non Sung district, Nakhon Ratchasima Province, Northeast of Thailand

\begin{tabular}{lcc}
\hline Demographic data & No. of participant & $\%$ \\
\hline Age (years old) & & \\
$30-40$ & 113 & 23.8 \\
$41-50$ & 89 & 42.6 \\
$51-60$ & & 33.6 \\
Education & 11 & 4.2 \\
$\quad$ Un-educated & 81 & 30.6 \\
Primary school & 70 & 26.4 \\
Junior secondary school & 85 & 32.1 \\
Senior secondary school & 10 & 3.8 \\
Under-graduated & & \\
Marital status & 19 & 7.2 \\
Single & 22 & 85.0 \\
Marriage & 17 & 6.4 \\
Widow & 4 & 1.5 \\
Divorced & & \\
Occupation (BHT) & 158 & 59.6 \\
Agriculture & 43 & 16.2 \\
Un-skill labor & 30 & 11.3 \\
Grocer & 21 & 7.9 \\
Housewife & 7 & 2.6 \\
Employee & & \\
Family income (BHT/month) & 96 & 36.2 \\
$\quad<5,000$ & 144 & 54.3 \\
6,000-10,000 & 25 & 9.4 \\
>10,000 & 265 & 100 \\
\hline Total & & \\
\hline & &
\end{tabular}

Table 2. Knowledge, attitude, and practice level regarding to cervical cancer of 265 participants from 8 villages of Lum Khao sub-district, Non Sung district, Nakhon Ratchasima Province, Northeast of Thailand

\begin{tabular}{lcc}
\hline Behaviors & $\begin{array}{c}\text { No. of participants } \\
(\mathrm{n}=265)\end{array}$ & $\%$ \\
\hline Knowledge & & \\
High & 168 & 63.4 \\
Fair & 65 & 24.5 \\
Low & 32 & 12.1 \\
Attitude & & \\
$\quad$ Good & 23 & 8.7 \\
$\quad$ Moderate & 182 & 68.7 \\
Poor & 60 & 22.6 \\
Practice & & \\
Regular & 109 & 41.1 \\
Irregular & 129 & 48.7 \\
$\quad$ Never & 27 & 10.2 \\
\hline
\end{tabular}

"Screening of cervical cancer; disadvantage to them". Of $41.1 \%, 48.7 \%$, and $10.2 \%$ participants had regularly, irregularly, and never screened CC, respectively. Majority of participants who screened $\mathrm{CC}$ was 1,2 , and $>2$ times, as $40.8 \%, 32,1 \%$, and $16.9 \%$, respectively. While, $10.2 \%$ of participants who had no CC screened, had a reason with being shied $(44.4 \%)$ and have no time $(55.6 \%)$. Vaginal discharge and itching were the common causes of sign and symptom of participants who received $\mathrm{CC}$ screened at health promotion hospital of sub-district (Table 3).
Table 3. Practice regarding to cervical cancer screening of 265 participants from 8 villages of Lum Khao sub-district, Non Sung district, Nakhon Ratchasima Province, Northeast of Thailand

\begin{tabular}{lrr}
\hline $\begin{array}{l}\text { Cervical cancer } \\
\text { screening }\end{array}$ & $\begin{array}{c}\text { No. } \\
\text { of participants }\end{array}$ \\
\hline Number of CC screening & 265 & \\
Never & 27 & 10.2 \\
1 time & 108 & 40.8 \\
2 times & 85 & 32.1 \\
$>2$ times & 45 & 16.9 \\
Reason of participants who had no CC screening & 27 & \\
Be shy & 12 & 44.4 \\
Have no time & 15 & 55.6 \\
Service places for CC screening & 238 & \\
Health promotion hospital of sub-district & 207 & 87.0 \\
District hospital & 31 & 13.0 \\
Sign and symptom before received CC screening & 238 & \\
Vaginal discharge & 18 & 7.6 \\
Vaginal itching & 8 & 3.4 \\
None & 212 & 89.0 \\
\hline
\end{tabular}

\section{Discussion}

Nationwide campaign of $\mathrm{CC}$ screening of women between 30-60 years old is conducted in Thailand. In this campaign, for a success of Thai health policy, women at risk must have screened $\mathrm{CC}$ more than $60 \%$ among five years periods (2009-2011). However, in Lum Khao sub-districts, Non Sung district, Nakhon Ratchasima province, Thailand, only $8 \%$ of them had screened CC (Health promotion hospital of Lum Khao sub-district 2014). This data shows a low awareness of women in the rural community. Recent study, the majority of them was age between 41-50 years old and had the marriage status as $85.0 \%$. This group is a high risk for CC because of having a sexual partner may induced $\mathrm{CC}$ occur. The $12.1 \%$ of participants had low knowledge regarding to $\mathrm{CC}$, particularly the low score in the question of "Starting sex at a young age is a risk factor to CC". This rural women required improvement of their knowledge. Risk factors had been reported that starting sex at young age and in those having many sexual partners related to CC occurs (Kumar et al., 2007; Hong et al., 2009; Stewart and Wild, 2014). In addition, participants had a low score of "Longterm use of combined oral contraceptives is associated with an increased risk of CC'. Moreno et al. (2002) has been reported that oral contraceptives effect on risk of cervical cancer in women with human papillomavirus infection. While, Brisson et al. (1994) indicates that birth control pills related to increasing $\mathrm{CC}$.

Of $22.6 \%$ participants had a poor attitude regarding screened CC. The low scores were found in the question of "Screening of CC, disadvantage to them", and followed "Screening of CC, non-necessary for them". Of 10.2\% participants had never screened for CC, they had the reason of being shied and have no time. This result indicates that people require changing of attitude and practice to screen CC. Personal invitations encouraging women to get screened are effective at increasing the likelihood that they will do so. Educational materials help 
Cholticha Mongsawaeng et al

to increase the likelihood of women going for screening (Everett et al., 2011). In developed countries, checking the cervix for $\mathrm{CC}$ has been credited with dramatically reducing the number of cases and mortality from CC (Canavan and Doshi, 2000). Pap smear is the method used for CC screen that can identify precancerous changes which when treated can prevent the development of cancer (World Health Organization 2014). Pap smear screening every 3-5 years with appropriate follow-up can reduce $\mathrm{CC}$ incidence by up to $80 \%$ (Arbyn et al., 2010). Participants who had CC screened, came to screen with signs and symptoms of vaginal discharge and itching. Abnormal results may suggest the presence of pre-cancerous changes allowing further examination and possible preventive treatment. $\mathrm{CC}$ is due to the abnormal growth of cells that has no symptoms in early stage, later symptoms may include abnormal vaginal bleeding, discharge, and itching, and pelvic pain (Stewart and Wild, 2014). All abnormal cases were suggested to be confirmed with the rapid laboratory in district hospital.

This study indicates that $\mathrm{CC}$ is still a health problem in the rural community. Some people are lack of knowledge, attitude, and practice. Therefore, health education is required, particularly in those who never had CC screened.

\section{Acknowledgements}

This research was supported a grant by the faculty of Public Health, Vongchavalitkul University. We would like to thanks all staffs at the health promotion hospital of Lum Khao sub-district, Non Sung district, Nakhon Ratchasima province, for their assistant. Special thanks for village health volunteers at Lum Khao sub-district for their data collected.

\section{References}

Arbyn M, Anttila A, Jordan J, et al (2010). European guidelines for quality assurance in cervical cancer screening; 2ndsummary document. Ann Oncol, 21, 448-58.

Best JW (1997). Research in education. $3^{\text {rd }}$ ed. eglewood cliff: Prentce Hall, Inc.

Bloom BS (1971). Handbook on formative and summative of student learning. New York: Mc Graw-Hill Book Company.

Brisson J, Morin C, Fortier M, et al (1994). Risk factors for cervical intraepithelial neoplasia: differences between lowand high-grade lesions. Am J Epidemiol, 140, 700-10.

Canavan TP, Doshi NR (2000). Cervical cancer. Am Fam Physician, 61, 1369-76.

Everett T, Bryant A, Griffin MF, et al (2011). Interventions targeted at women to encourage the uptake of cervical screening. Cochrane Database Systematic Rev, 5, 2834.

Health promotion hospital of Lum Khao sub-district (2014). Annual report of outpatient 2014. Health promotion hospital of Lum Khao sub-district, District Public Health of Non Sung, Provincial Public health of Nakhon Ratchasima, Ministry of Public Health, Thailand.

Hong WK, Bast RC, Hait WN, et al (2009). Holland frei cancer medicine. $8^{\text {th }}$ ed. New York: McGraw-Hill Med, 1299.

Krejcie RV, Morgan DW (1970). Determining sample size for research activities. Edu Psy Measure, 30, 607-10.

Kumar V, Abbas AK, Fausto N, et al (2007). Robbins Basic Pathology. $8^{\text {th }}$ ed. Saunders Elsevier, 718-21.
Marks MA, Gupta S, Liaw KL, et al (2015). Prevalence and correlates of HPV among women attending family-planning clinics in Thailand. BMC Infect Dis, 15, 159.

Moreno V, Bosch FX, Munoz N, et al (2002). Effect of oral contraceptives on risk of cervical cancer in women with human papillomavirus infection: the IARC multicentric case-control study. Lancet, 359, 1085-92.

Stewart BW, Wild CP (2014). World Cancer Report 2014. The international agency for research on cancer, world health organization, WHO press. 630.

Vaccarella S, Lortet-Tieulent J, Plummer M, et al (2013). Worldwide trends in cervical cancer incidence: impact of screening against changes in disease risk factors. Eur $J$ Cancer, 49, 3262-73.

World Health Organization (2014). Comprehensive cervical cancer control; A guide to essential practice $-2^{\text {nd }}$. WHO Press, 364 pages. 